University of Wollongong

Research Online

Faculty of Engineering and Information

Faculty of Engineering and Information

Sciences - Papers: Part A

Sciences

$1-1-2016$

\title{
Experimental and numerical study on the effect of ZDDP films on sticking during hot rolling of ferritic stainless steel strip
}

\author{
Liang Hao \\ Xidian University, Ih421@uowmail.edu.au \\ Zhengyi Jiang \\ University of Wollongong, jiang@uow.edu.au \\ Dongbin Wei \\ University of Wollongong, dwei@uow.edu.au \\ Dianyao Gong \\ Northeastern University \\ Xiawei Cheng \\ University of Wollongong, xiawei@uow.edu.au
}

See next page for additional authors

Follow this and additional works at: https://ro.uow.edu.au/eispapers

Part of the Engineering Commons, and the Science and Technology Studies Commons

Research Online is the open access institutional repository for the University of Wollongong. For further information contact the UOW Library: research-pubs@uow.edu.au 


\title{
Experimental and numerical study on the effect of ZDDP films on sticking during hot rolling of ferritic stainless steel strip
}

\author{
Abstract \\ The aim of this study is to investigate the effect of zinc dialkyl dithio phosphate (ZDDP) films on sticking \\ during hot rolling of a ferritic stainless steel strip. The surface characterization and crack propagation of \\ the oxide scale are very important for understanding the mechanism of the sticking. The high- \\ temperature oxidation of one typical ferritic stainless was conducted at $1373 \mathrm{~K}\left(1100^{\circ} \mathrm{C}\right)$ for \\ understanding its microstructure and surface morphology. Hot-rolling tests of a ferritic stainless steel \\ strip show that no obvious cracks among the oxide scale were observed with the application of ZDDP. A \\ finite element method model was constructed with taking into consideration different crack size ratios \\ among the oxide scale, surface profile, and ZDDP films. The simulation results show that the width of the \\ crack tends to be reduced with the introduction of ZDDP films, which is beneficial for improving sticking.

\section{Keywords} \\ rolling, effect, ferritic, study, during, stainless, sticking, numerical, steel, experimental, strip, hot, films, zddp

\section{Disciplines} \\ Engineering | Science and Technology Studies

\section{Publication Details} \\ Hao, L., Jiang, Z., Wei, D., Gong, D., Cheng, X., Zhao, J., Luo, S. \& Jiang, L. (2016). Experimental and \\ numerical study on the effect of ZDDP films on sticking during hot rolling of ferritic stainless steel strip. \\ Metallurgical and Materials Transactions A: Physical Metallurgy and Materials Science, 47 (10), \\ 5195-5202.
}

\section{Authors}

Liang Hao, Zhengyi Jiang, Dongbin Wei, Dianyao Gong, Xiawei Cheng, Jingwei Zhao, Suzhen Luo, and Laizhu Jiang 


\section{Experimental and numerical study on the effect of ZDDP films on sticking during hot rolling of ferritic stainless steel strip}

Liang Hao ${ }^{\mathrm{a}}$, Zhengyi Jiang ${ }^{\mathrm{a}}$, Dongbin $\mathrm{Wei}^{\mathrm{b}}$, Dianyao Gong ${ }^{\mathrm{c}}$, Xiawei Cheng ${ }^{\mathrm{a}}$, Jingwei Zhao ${ }^{\mathrm{a}}$, Suzhen Luo ${ }^{\mathrm{d}}$ and Laizhu Jiang ${ }^{\text {d }}$

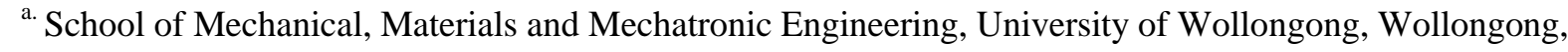
NSW 2522, Australia;

${ }^{\mathrm{b} .}$ School of Electrical, Mechanical and Mechatronic Systems, University of Technology Sydney, Sydney NSW 2007, Australia;

c. State Key Laboratory of Rolling and Automation, Northeastern Univertity, Shengyang 110004, P.R. China;

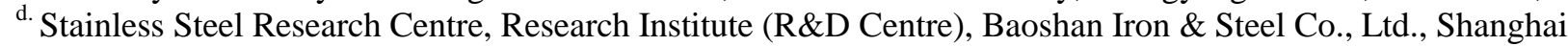
200431, P.R. China.

Abstract: The aim of this study is to investigate the effect of zinc dialkyl dithio phosphate (ZDDP) films on sticking during hot rolling of a ferritic stainless steel strip. The surface characterization and crack propagation of the oxide scale are very important for understanding the mechanism of the sticking. The high-temperature oxidation of one typical ferritic stainless was conducted at $1373 \mathrm{~K}\left(1100{ }^{\circ} \mathrm{C}\right)$ for understanding its microstructure and surface morphology. Hot-rolling tests of a ferritic stainless steel strip show that no obvious cracks among the oxide scale were observed with the application of ZDDP. An finite element method (FEM) model was constructed with taking into consideration different crack size ratios among the oxide scale, surface profile, and ZDDP films. The simulation results show that the width of the crack tends to be reduced with the introduction of ZDDP films, which is beneficial for improving sticking.

Keywords: Hot rolling, ferritic stainless steel, sticking, ZDDP, FEM

\section{Introduction}

Since hot rolling is a mill process that involves rolling the metal at a high temperature in an open atmosphere, oxidation of the metal is inevitable. The oxide scale can deform plastically or fracture, and its behavior will have a considerable impact on the surface quality of the formed products. According to the reports ${ }^{[1]}$, approximately 30 pct of the surface defects can be related to the behavior of the oxide scale. One surface defect is called "sticking", which refers to a phenomenon where fragments of the rolled strips are detached and get stuck to the work roll

*Corresponding author. Tel: +61-2-42214744; Fax: +61-2-42215474.

Email address: Ih421@uowmail.edu.au (Liang Hao), jiang@uow.edu.au (Zhengyi Jiang) 
surface, causing surface defects on the mill products and scoring on the roll surface, which frequently occurs during hot rolling of ferritic stainless steels ${ }^{[2]}$. It has been found that sticking did not occur in the surface region containing oxides, whereas it occurs in the surface region without oxides ${ }^{[3]}$. During hot rolling, a large reduction proceeded. The extension of the thin oxide scale formed on ferritic stainless steels cannot fully cover the substrate. Therefore, the fresh substrate is bound to make contact with the work roll surface. In addition, the higher the content of $\mathrm{Cr}$ in alloys, the more likely it is to suffer sticking because a thinner oxide scale was

formed ${ }^{[4]}$. With the development of new ferritic stainless steels with higher content of $\mathrm{Cr}$ in the future, it is very significant to put forward the effective measure against sticking in practice.

Extreme pressure (EP) agents are one of the most important constituents in lubricants, ${ }^{[5]}$ which can form a solid film, acting as a boundary lubricant and preventing the substrate from directly contacting the work roll surface. Zinc dithiophosphates (ZDDPs) are arguably the most successfully lubricant additives ever invented. They were introduced over 60 years ago, have been in continuous use ever since, and are still being employed in practically all current engine oils. As well as being remarkable in their performance, ZDDPs have also been astonishingly successfully in their ability to inspire research ${ }^{[6]}$. In the previous study ${ }^{[7]}$, ZDDP has been selected as the most effective EP agent and has been suggested for further hot rolling tests. In this article, high-temperature oxidation of one ferritic stainless steel was carried out to characterize the oxide scale and surface roughness. Additionally, hot rolling tests of ferritic stainless steel were also conducted on a 2-high Hill-100 experimental rolling mill to evaluate the effect of ZDDP on the deformation behavior of the oxide scale. The inaccessibility of the interface between the hot strip and the work roll surface greatly restricts the understanding of the sticking mechanism; thus, an FEM model has been constructed to help interpret the deformation behavior of the oxide scale.

\section{Experimental and FEM model}

\subsection{Experimental}

The main chemical composition of one typical ferritic stainless steel B445J1M which frequently suffered sticking is shown in Table 1 . The specimens with the dimensions of $10 \times 10 \times 3 \mathrm{~mm}^{3}$ were prepared. All specimens were ground by 1200 grit SiC paper before the oxidation tests, and 
they were held for $0.5,1,1.5$, and 2 hours at $1373 \mathrm{~K}\left(1100{ }^{\circ} \mathrm{C}\right)$ in an electrical resistance furnace. The surfaces of samples after the oxidation were characterized under a Keyence VK-X100/X 200 Laser Scanning Microscope and its cross-section images were ground, polished, and then analyzed under a scanning electron microscope (SEM).

The samples for hot-rolling tests were machined into the dimensions of $400 \times 100 \times 10 \mathrm{~mm}^{3}$ and heated to $1373 \mathrm{~K}\left(1100{ }^{\circ} \mathrm{C}\right)$ in an electrical resistance furnace. Reductions of 20 pct and 30 pct were employed with and without applying 0.5 pct ZDDP in distilled water on a 2-high Hill-100 experimental rolling mill. For each test, $200 \mathrm{~mL}$ lubricant solutions were sprayed on the roll surface before hot rolling, and acetone was used to clean the rolls during the rolling interval. The rolled specimens cooled to room temperature in air.

\subsection{Generation of surface roughness asperity}

Within a small rectangular area $x_{1} \leq x \leq x_{2}$ and $y_{1} \leq y \leq y_{2}$, it is assumed that the shape of a surface roughness can be described by a norm function: ${ }^{[8,9]}$

$$
z=A \times e^{-\left[(x-\mu) / \sigma_{x}^{2}+(y-v) / \sigma_{y}^{2}\right] / 2}
$$

where $z$ and $A$ are the height and the peak height of the roughness asperity, respectively; $\mu$ and $v$ are the summit coordinates of the roughness asperity, respectively; and $\sigma_{x}$, and $\sigma_{y}$ are standard deviations that reflect the wavelength and sharpness of the roughness asperity, respectively.

For a section of the surface, the surface roughness can be expressed as:

$$
z=A \times e^{-(x-\mu) / 2 \sigma_{x}^{2}}, x_{1} \leq x \leq x_{2}
$$

At the boundaries $x_{1}, x_{2}, y_{1}, y_{2}$, each roughness asperity is connected with another asperity in the adjacent areas. To ensure that the outlines of the roughness asperity can be linked smoothly to form a rough roughness, let: 


$$
\begin{gathered}
\sigma_{x}=\left(x_{2}-x_{1}\right) / 6=\lambda_{x} / 6 \\
\sigma_{y}=\left(y_{2}-y_{1}\right) / 6=\lambda_{y} / 6
\end{gathered}
$$

where $\lambda_{x}$ and $\lambda_{y}$ are the wavelengths of the roughness asperity in $x$ - and $y$-directions, respectively. The height of every roughness asperity in the boundary of the rectangular area is close to 0 . The summit of a roughness profile is the small rectangle so that $\mu$ and $\nu$ can be determined. For a rough surface, the height $A$ and the wavelengths $\lambda_{x}, \lambda_{y}$ are random numbers. $A$, $\lambda_{x}$, and $\lambda_{y}$ are assumed to have a normal distribution in a specified rough surface [10].

\subsection{FEM model}

In the hot-rolling process, the strip width is much larger than its thickness. Thus, the deformation along the width direction can be neglected, and work rolls and the strip can be simplified to an upsetting process, in which the work roll is taken as a straight line. Its circular motion can be decomposed into a horizontal speed $V_{x}$ and a vertical speed $V_{y}$, which can be determined through the forward slip, work roll speed, and geometrical relationship between the work roll and the strip. The boundary conditions for the research object are as follows: The bottom edge is set to be $y$-axis symmetric, whereas the right edge is set to be $\mathrm{x}$-axis symmetric. The work roll is taken as a rigid body, and the strip is considered to be a plastic body.

The average roughness and thickness of the oxide scale in the FEM model is $1.5 \mu \mathrm{m}$ and $4.6 \mu \mathrm{m}$, respectively, which refers to the $\mathrm{B} 445 \mathrm{~J} 1 \mathrm{M}$ oxidized at $1373 \mathrm{~K}\left(1100{ }^{\circ} \mathrm{C}\right)$ for 2 hours. The relative movement between the oxide scale and the substrate is constrained by Coulomb friction. 4-node bilinear plane strain quadrilateral elements are used. The simulation conditions are rolling temperature $1373 \mathrm{~K}\left(1100{ }^{\circ} \mathrm{C}\right)$, rolling speed $0.42 \mathrm{~m} / \mathrm{s}$. The steel with a rough oxide scale of 20

pet reduction is calculated. Mosey et al. ${ }^{[11-13]}$ found that the decomposition of ZDDP form highly cross-linked networks under temperatures of 100-1000 K (-173 - $\left.727^{\circ} \mathrm{C}\right)$ and high pressure by Car-Parrinello molecular dynamic (CPMD), and its bulk modulus is $140 \mathrm{GPa}$. 
The crack may preexist or occur in the oxide scale during the rolling process. ${ }^{[14-18]}$ In this model, the cracks are assumed to preexist in the oxide scale, and no new cracks form during hot rolling. Five cracks with the ratio of crack width to thickness $0.4,0.6,0.8,1.0$, and 1.2 are constructed. A simulation was carried out using Abaqus FEA Explicit software package. The FEM model without and with ZDDP are shown in Figure 1.

\section{Results and discussion}

\subsection{Characterization of oxide scale}

The arithmetical average roughness profile $\left(R_{a}\right)$ and mean width of the roughness profile elements $\left(R_{S m}\right)$ are often used to characterize the surface roughness, and they are measured under the Keyence VK-X100/X200 laser scanning microscope. The results are summarized in Figure 2, and three groups of measurements on each sample are present.

Figure 3 shows SEM X-ray maps for the cross section of B445J1M after the oxidation at 1373 $\mathrm{K}\left(1100{ }^{\circ} \mathrm{C}\right)$ for $2 \mathrm{~h}$. It is clearly seen that the oxide layer is rich in $\mathrm{Cr}$ and $\mathrm{O}$. Si obviously marks the distinction between the oxide scale and the substrate. Therefore, the oxide layer of B445J1M can be considered as a single layer of $\mathrm{Cr}_{2} \mathrm{O}_{3}$. Additionally, the separation can be clearly observed between the oxide scale and the substrate, which means the oxide scale of B445J1M poorly attached to the substrate [19]. Figure 4 shows the thickness of the B445J1M oxide scale vs time, from which can be obtained that its thickness reaches at approximately 4.6 $\mu \mathrm{m}$ after oxidizing 2 hours.

\subsection{Hot-rolling tests}

Figure 5 shows SEM images of the deformation behaviour of the oxide scale on the rolled strips without and with ZDDP in the lubricant after 20 pct and 30 pct reductions. It is evident that the addition of ZDDP in the lubricant has a significant influence on the deformation behavior of the oxide scale. Without adding ZDDP (Figures 5(a) and (c)), the large cracks are observed in the oxide scale, from where fresh substrate can easily extrude out. Therefore, sticking could most likely occur, as mentioned. In contrast, when the EP agent ZDDP solution (Figures 5(b) and (d)) 
was used for hot rolling, the oxide scale was rolled into small particles, and the size of the cracks was small, which will be helpful to improve sticking defects.

\subsection{FEM simulation}

Because it is inaccessible to observe the interface between the hot strip and the work roll surface, the understanding of the sticking mechanism is greatly hampered. Thus, an FEM model has been constructed to help interpret the deformation behavior of the oxide scale.

In Alexander's program, ${ }^{[20]}$ the flow stress is modified in the following form:

$$
\sigma=A \cdot e^{a T} \cdot(1+B \varepsilon)^{n_{1}} \cdot(1+D \dot{\varepsilon})^{n_{2}}
$$

where $a, B, D, n_{1}$, and $n_{2}$ are constants assuming $D=B=1000 \gg 1$. Sufficiently, $A, a, n_{1}$, and $n_{2}$ in Eq. [5] are easily determined by multiple -regression.

To determine the flow stress model adapted by Alexander's program, compression tests were carried out for all eight steel grades on a Gleeble-3500 Hydro wedge test system under different temperatures and compression rates. The regression equation of ferritic stainless steel B445J1M according to Eq. [5] is expressed as Eq. [6]:

$$
\sigma_{s}=403.4288 \times e^{-0.0041 \times T} \times(1+1000 \varepsilon)^{0.1827} \times(1+1000 \dot{\varepsilon})^{0.1142}
$$

Echsler et al. ${ }^{[21]}$ found that the flow stress strain curve of the oxide scale was similar to that of the substrate steel in a 4-point bend test and that the oxide scale shows plastic-creep deformation. In this simulation, the flow stress of the oxide scale is assumed to be proportional to that of steel substrate and can be expressed by Eq. [7]:

$$
\sigma_{o}=k \sigma_{s}
$$

where $\sigma_{o}$ and $\sigma_{s}$ are the flow stress of the oxide scale and the substrate, respectively; $k$ is the proportional constant. 
Cheng et al. ${ }^{[19]}$ found that the oxide scale of B445J1M is harder than the matrix. Therefore, a series of simulations with same rolling and profile parameters but different $k(1.2,1.5$, and 1.8$)$ were carried in FEM calculation. Similar results were obtained. Considering the length of the article, only the case with $k=1.5$ is presented. Figure 3 shows that the oxide scales of ferritic stainless steel B445J1M are mainly chromium oxide $\left(\mathrm{Cr}_{2} \mathrm{O}_{3}\right)$. The Poisson ratio is 0.29 , and Young's modulus of chromium oxide is calculated by Eqs. [8] and [9]:[22]

$$
\begin{gathered}
G_{o x}(T)=G_{o x}^{0}\left(1+\frac{T-300}{T_{M}} \cdot \frac{T_{M}}{G_{o x}^{0}} \cdot \frac{d G}{d T}\right) \\
E=2 \times G_{o x}(T) \cdot(1+v)
\end{gathered}
$$

where $T$ is temperature in $\mathrm{K}, T_{M}$ is the melting point $(\mathrm{K}), v$ is the Poisson ratio, $G^{o}{ }_{o x} i s$ the shear modulus at $300 \mathrm{~K}\left(27^{\circ} \mathrm{C}\right), G_{o x}(T)$ is the shear modulus at the temperature of $T$, and $E$ is Young's modulus; all moduli are in $\mathrm{MPa}$. For $\mathrm{Cr}_{2} \mathrm{O}_{3}$ :

$$
\begin{aligned}
& G_{o x}^{o}=1.30 \times 10^{5} \\
& T_{M}=2710 \\
& \frac{T_{M}}{G_{o x}} \cdot \frac{d G}{d T}=-0.33
\end{aligned}
$$

Substituting the parameters in Eq. [10] into Eq. [9], the Young's modulus of $\mathrm{Cr}_{2} \mathrm{O}_{3}$ at $1373 \mathrm{~K}$ $\left(1100{ }^{\circ} \mathrm{C}\right)$ is $1.13 \times 10^{5} \mathrm{MPa}$.

Figure 6 shows the deformed cracks with and without ZDDP films after deformation. It can be seen that the ZDDP films has an obvious influence on the crack propagation. Without ZDDP films (Figure 6(a)), the substrate tends to extrude through the cracks as their width increase. By contrast, with ZDDP films (Figure 6 (b)), the widths for cracks 1 and 2 are reduced to be nearly 
zero. The average widths for cracks 3,4 and 5 are $3.68 \mu \mathrm{m}, 4.60 \mu \mathrm{m}$, and $5.59 \mu \mathrm{m}$, respectively, which is still less than $3.72 \mu \mathrm{m}, 4.62 \mu \mathrm{m}$, and $5.62 \mu \mathrm{m}$ without ZDDP films. This means that ZDDP films can decrease crack propagation eventually improving sticking.

ZDDP films can reduce the crack width during hot rolling, which is proved by both hot-rolling tests and FEM simulation. The surface of the oxide scale is made up of complicated asperities. Thus, when the surfaces between rolls and strips are placed in contact in the roll bite, only the peaks of the asperities touch $[8,9]$. Rolling forces were applied by rolls to strips through such peaks in contact with each other, which compresses and shears the oxide scale and its substrate as well. Figure 7(a) schematically demonstrates the mechanism of the deformation behavior of the oxide scale without ZDDP films and the microscopic view of the contact interface in the roll bite. Compared with the roughness of the oxide scale, the roll surface is taken as smooth. It can be seen that the contacts only occurred at some asperities. This means that the oxide scale on the strip was subjected to a nonuniform force, producing a deformed oxide scale with large cracks after hot rolling, as shown in Figure 5(a). Figure 7(b) schematically demonstrates the mechanism of the deformation behavior of the oxide scale with the ZDDP films and its microscopic view of the contact interface in the roll bite. With ZDDP added to the lubricant for hot rolling, the ZDDP films filled the surface valleys and provided separation between the roll and the strip. Rolling forces were applied by rolls through the ZDDP films to the oxide scale on the strip. Consequently, the oxide scale was subjected to the uniform force, producing small particles of oxide scale after hot rolling.

\section{Conclusion}

Hot-rolling tests of ferritic stainless steel with the application of ZDDP show that no large cracks were observed. The mechanism of ZDDP films on the sticking mechanism lies in the fact that the rolling forces compressing through ZDDP films to the oxide scale are uniform, producing the deformed oxide scale with small particles. The function of ZDDP films on the crack propagation among the oxide scale has been analyzed through an FEM model, in which the surface profile is expressed by a norm function. High-temperature oxidation experiments of B445J1M were proceeded to characterize the surface roughness. Simulation results show that ZDDP films also 
can reduce the crack width among the oxide scale and separate the substrate from the work roll. Therefore, ZDDP is further suggested for industrial application.

\section{Acknowledgements}

The authors acknowledge financial support from the Baosteel - Australia Joint Centre, and using equipment from the UOW Electron Microscopy Centre (EMC).

\section{References}

[1] M. Krzyzanowski, J. H. Beynon and D. C. J. Farrugia: Oxide scale behaviour in high temperature metal processing, John Wiley \& Sons, Weinheim, 2010, pp. 1-3.

[2] W. Jin, J.-Y. Choi and Y.-Y. Lee: ISIJ International, 1998, vol. 38, pp. 739-43.

[3] D. J. Ha, H. K. Sung, S. Lee, J. S. Lee and Y. D. Lee: Mater. Sci. Eng., A, 2009, vol. 507, pp. 66-73.

[4] C. Zhang, Z. Liu, Y. Xu and G. Wang: J. Mater. Process. Technol., 2012, vol. 212, pp. 2183-92.

[5] S. Q. A. Rizvi: A Comprehensive Review of Lubricant Chemistry, Technology, Selection, and Design, ASTM International, West Conshohocken, PA, 2009, pp. 20-22.

[6] H. Spikes: Tribol. Lett., 2004, vol. 17, pp. 469-89.

[7] L. Hao, Z. Jiang, D. Wei, Y. Zhao, J. Zhao, M. Luo, L. Ma, S. Luo and L. Jiang: Tribol. Int, 2015, vol. 81, pp. $19-28$.

[8] Z. Y. Jiang, A. K. Tieu, W. H. Sun, J. N. Tang and D. B. Wei: Mater. Sci. Eng., A, 2006, vol. 435-436, pp. 434-38.

[9] J. Tang, A. K. Tieu and Z. Y. Jiang: J. Mater. Process. Technol., 2006, vol. 177, pp. 126-29.

[10] J. Tang, A. K. Tieu and Z. Y. Jiang: Key Eng. Mater., 2004, vol. 274-276, pp. 499-505.

[11] N. J. Mosey and T. K. Woo: Tribol. Int, 2006, vol. 39, pp. 979-93.

[12] N. J. Mosey, T. K. Woo, M. Kasrai, P. R. Norton, G. M. Bancroft and M. H. Müser: Tribol. Lett, 2006, vol. 24, pp. 105-14.

[13] N. J. Mosey, T. K. Woo and M. H. Müser: Phys. Rev. B, 2005, vol. 72, pp. 054124-1-6.

[14] M. Krzyzanowski and J. H. Beynon: ISIJ International, 2006, vol. 46, pp. 1533-47.

[15] M. Krzyzanowski and J. H. Beynon: J. Mater. Process. Technol., 2002, vol. 125-126, pp. 398-404.

[16] M. Krzyzanowski and J. H. Beynon: Modell. Simul. Mater. Sci. Eng., 2000, vol. 8, pp. 927-45.

[17] M. Krzyzanowski, J. H. Beynon and C. M. Sellars: Metall. Mater. Trans. B, 2000, vol. 31, pp. 1483-90.

[18] Y. H. Li and C. M. Sellars: J. Mater. Process. Technol, 1998, vol. 80-81, pp. 282-86.

[19] X. Cheng, Z. Jiang, D. Wei, J. Zhao, B. J. Monaghan, R. J. Longbottom and L. Jiang: Surf. Coat.

Technol., 2014, vol. 258, pp. 257-67.

[20] J. M. Alexander and R. C. Brewer: Manufacturing Technology, Ellis Horwood Ltd., West Sussex, pp.

[21] H. Echsler, S. Ito and M. Schütze: Oxid. Met., 2003, vol. 60, pp. 241-69.

[22] M. Schütze: Protective oxide scales and their breakdown, Wiley, Chichester, 1997, pp. 39-43. 


\section{Table Captions:}

Table 1 Main chemical composition of B445J1M (wt pct) [7] 


\section{A list of figure captions}

Figure 1 FEM models (a) without and (b) with ZDDP films

Figure 2 Experimental results: (a) average roughness and (b) mean width of the roughness profile

Figure 3 SEM X-ray maps for the cross section of B445J1M sample after the oxidation at 1373 $\mathrm{K}\left(1100{ }^{\circ} \mathrm{C}\right)$ for $2 \mathrm{~h}$

Figure 4 Thickness of the oxide scale formed vs time

Figure 5 SEM images of the deformation behaviour of the oxide scale on the rolled strips: 20 pct reduction (a) without ZDDP and (b) with ZDDP, and 30 pct reduction (c) without ZDDP and (d) with ZDDP

Figure 6 Deformation behaviour of cracks after 20 pct reduction (a) without and (b) with ZDDP films

Figure 7 Mechanism of the deformation behaviour of the oxide scale in the roll bite (a) without and (b) with ZDDP films [7] 


\begin{tabular}{cccccc}
\multicolumn{6}{c}{ Table 1 Main chemical composition of B445J1M (wt \%) [7] } \\
\hline Fe & $\mathrm{Cr}$ & $\mathrm{Mo}$ & $\mathrm{Si}$ & $\mathrm{Mn}$ & $\mathrm{Ni}$ \\
& & & & & \\
\hline Balance & 21.5 & 0.6 & 0.3 & 0.15 & 0.00 \\
\hline
\end{tabular}


(a)
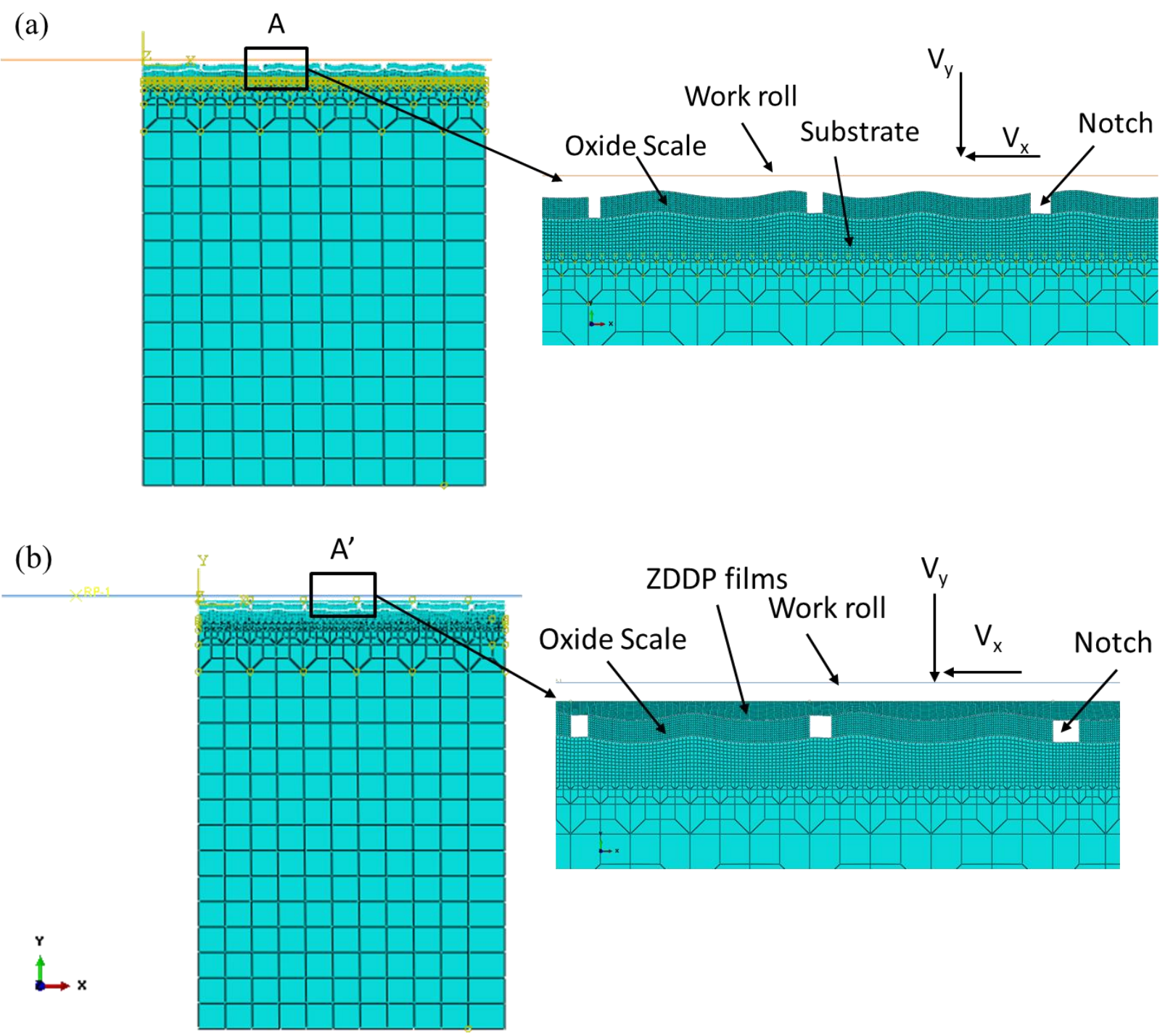

Figure 1 FEM models (a) without and (b) with ZDDP films 


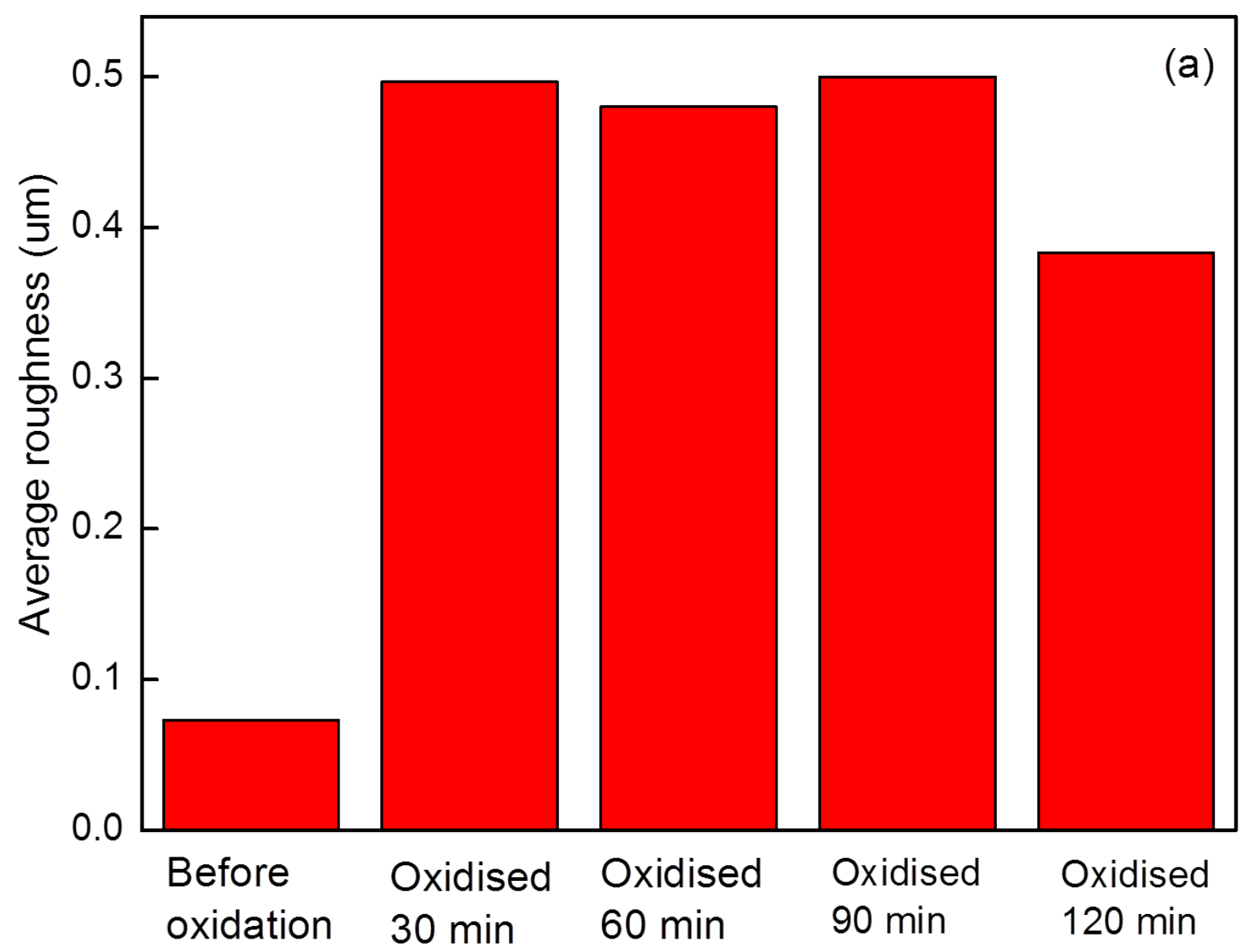




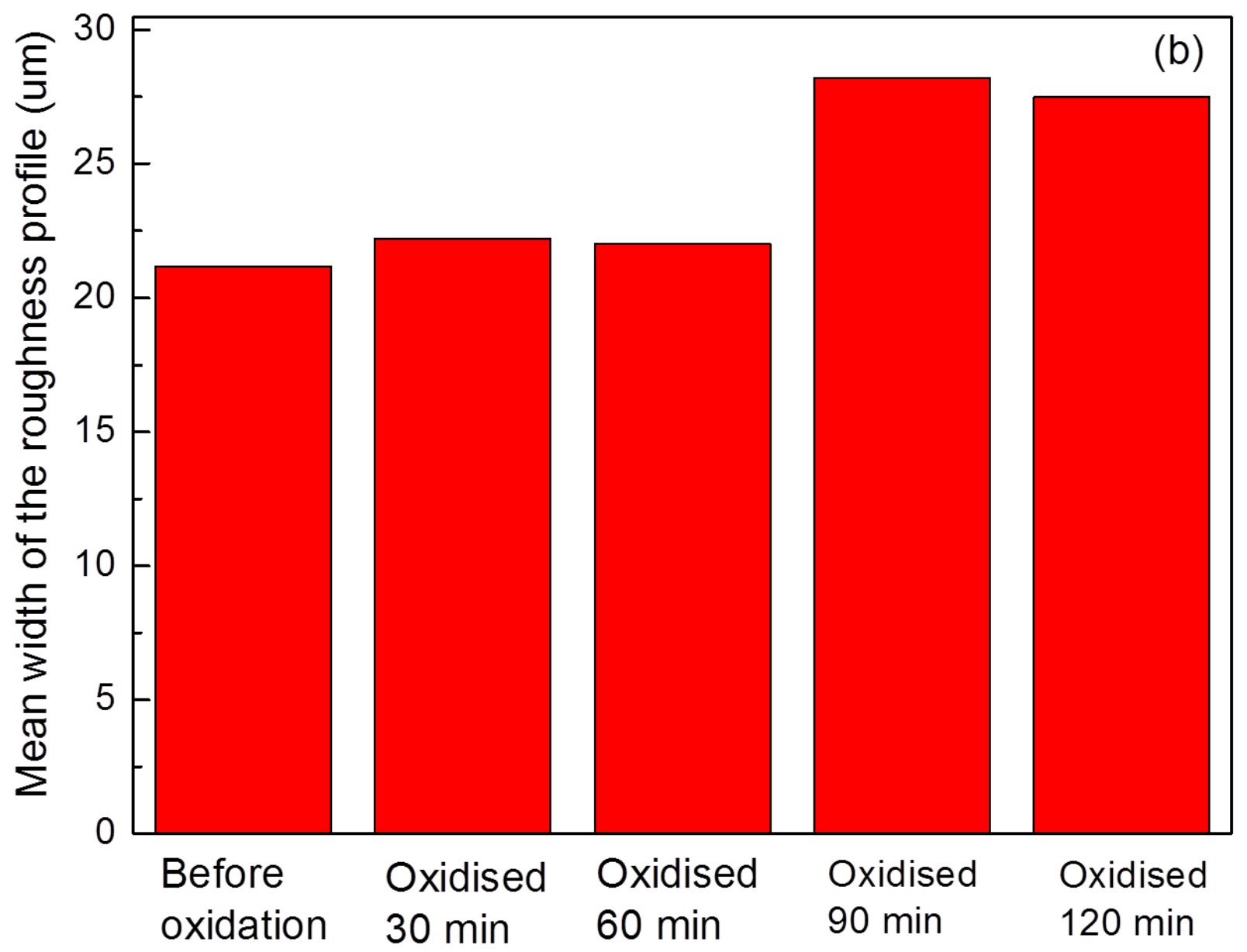

Figure 2 Experimental results: (a) average roughness and (b) mean width of the roughness profile 


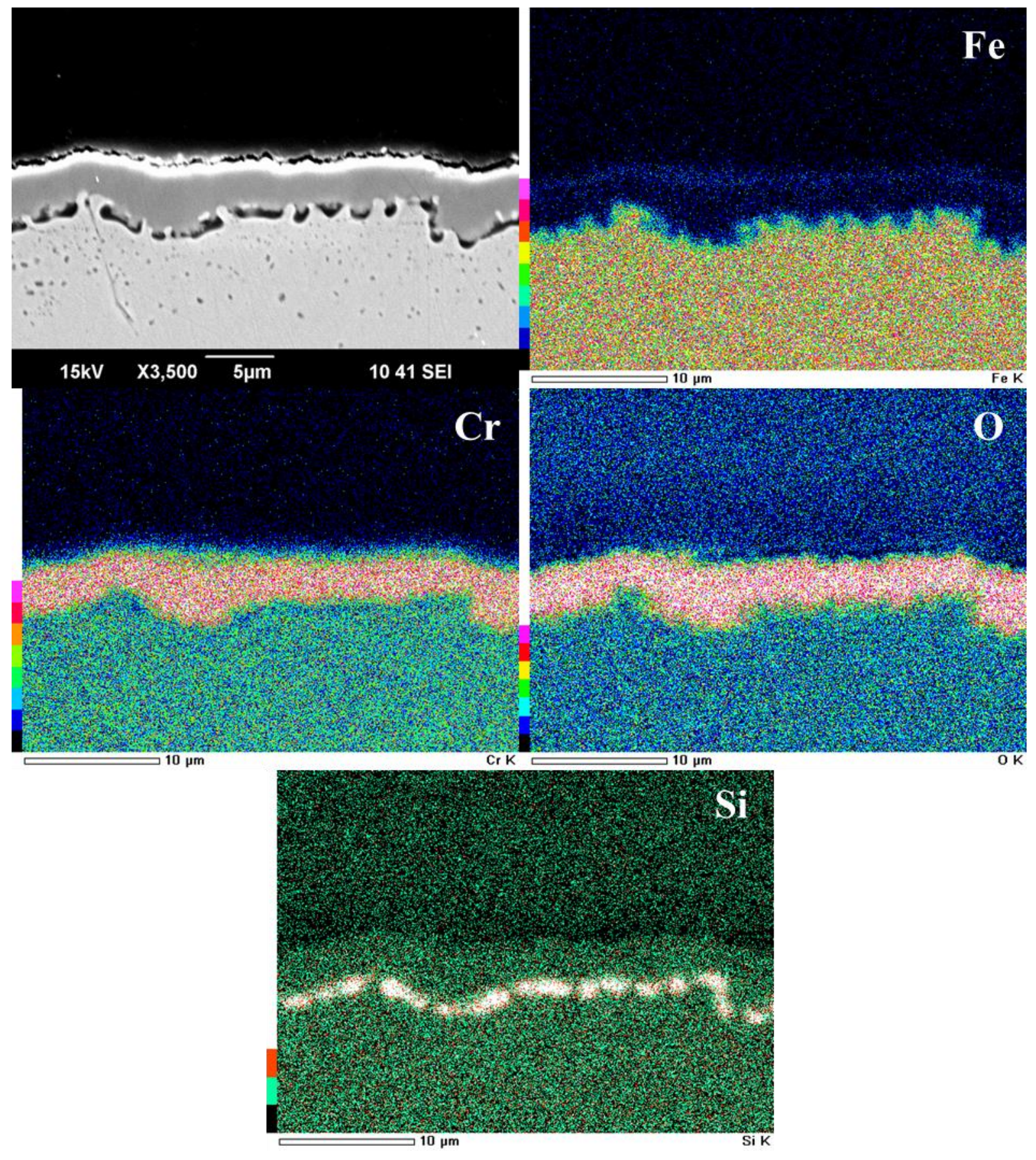

Figure 3 SEM X-ray maps for the cross section of B445J1M sample after the oxidation at 1373 $\mathrm{K}\left(1100{ }^{\circ} \mathrm{C}\right)$ for $2 \mathrm{~h}$ 


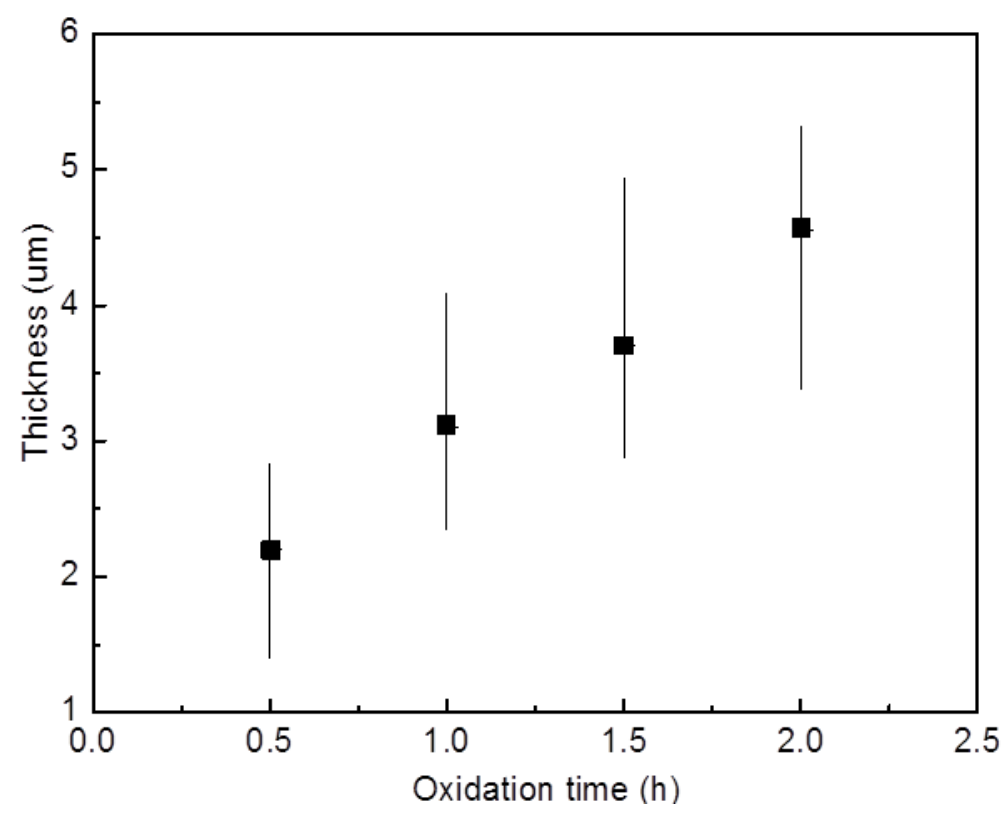

Figure 4 Thickness of the oxide scale formed vs time 
(a)

Oxide scale

Resin

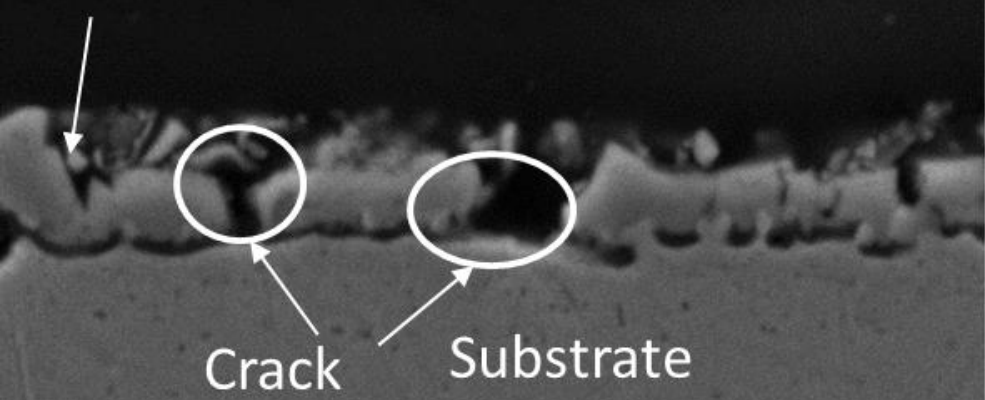

$15 \mathrm{kV} \quad \times 5,0 \overline{5 \mu 0}$

1045 SEI

(b)

Oxide scale

Resin

Substrate 

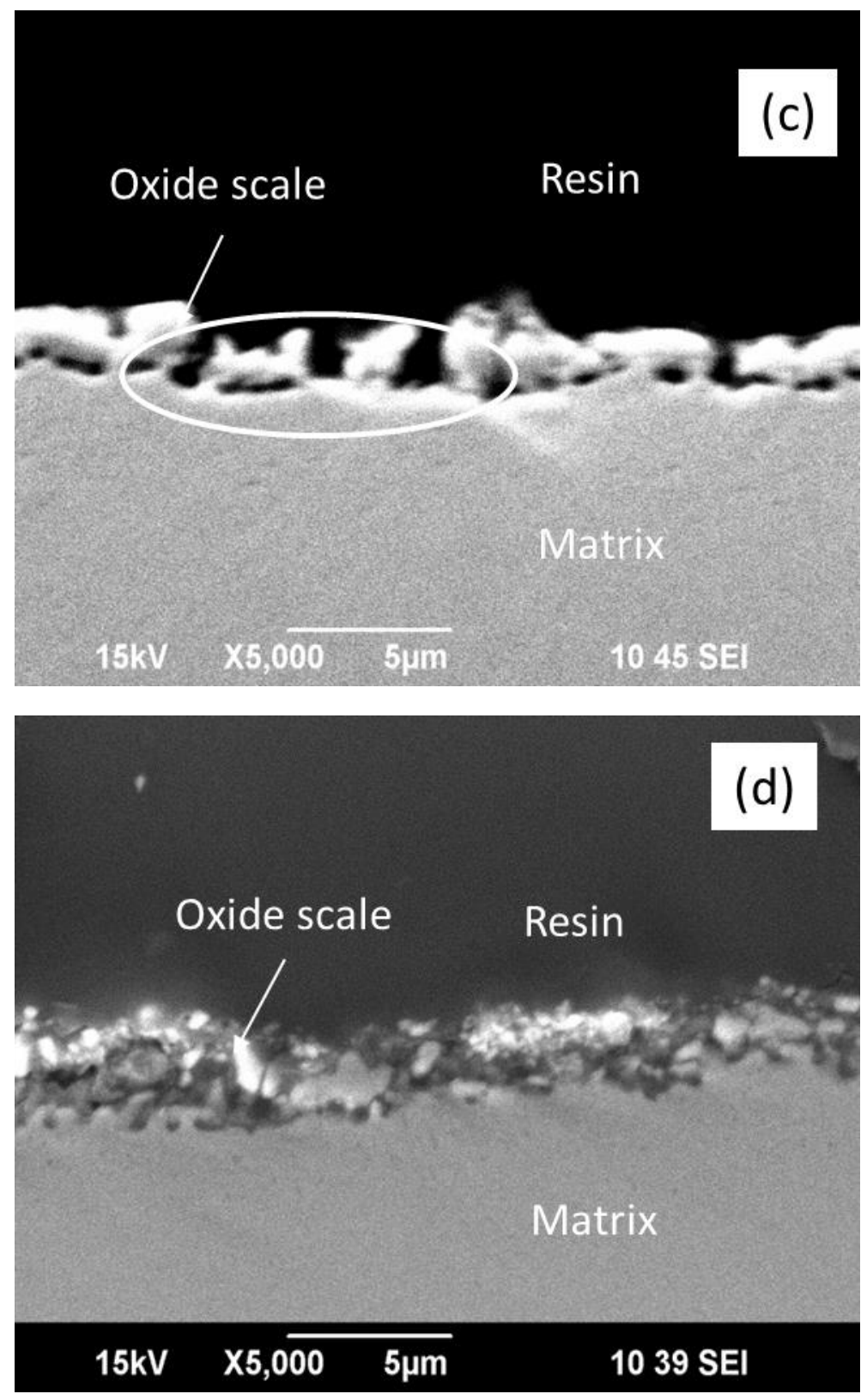

Figure 5 SEM images of the deformation behaviour of the oxide scale on the rolled strips: 20 pct reduction (a) without ZDDP and (b) with ZDDP, and 30 pct reduction (c) without ZDDP and (d) with ZDDP 
Crack 1

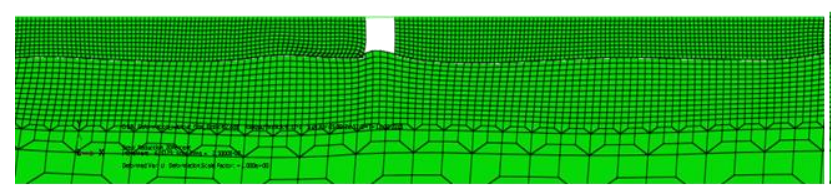

Crack 3

Crack 4
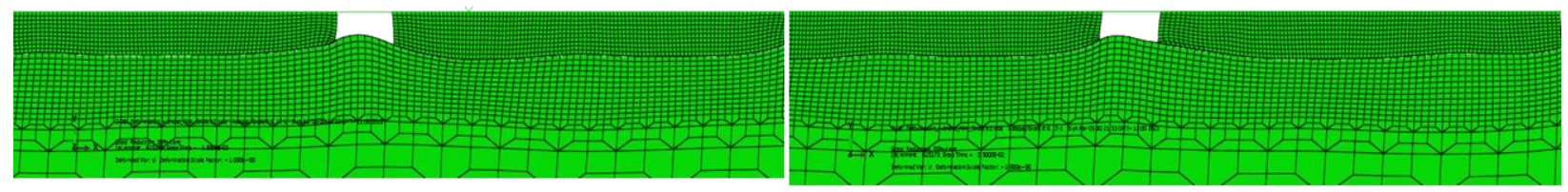

Crack 5

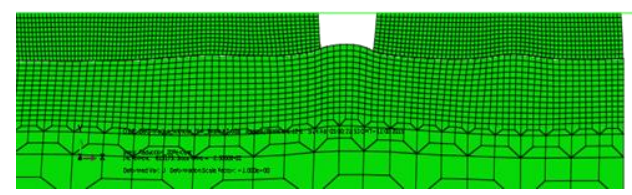

(b)
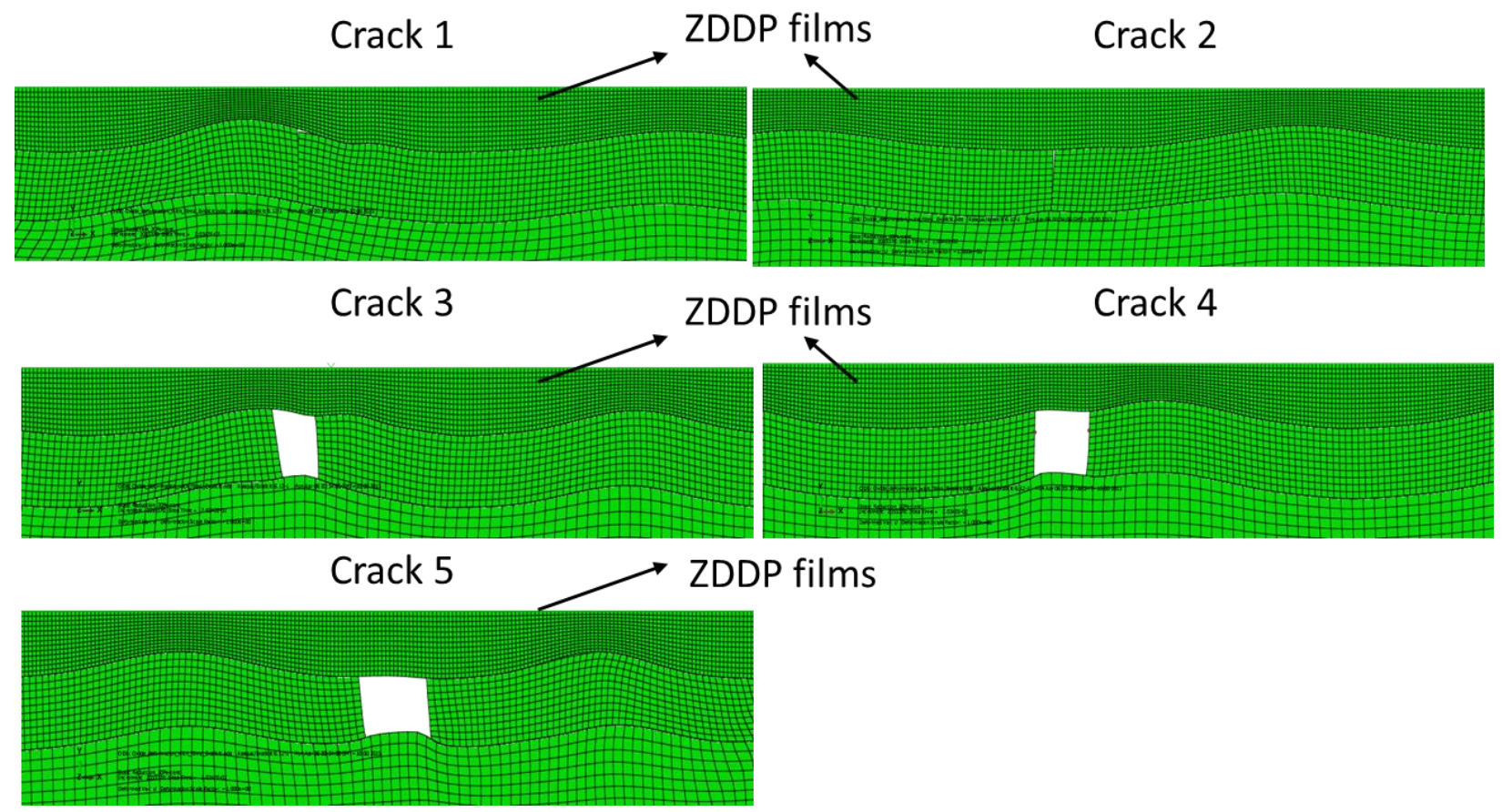

Figure 6 Deformation behaviour of cracks after 20 pct reduction (a) without and (b) with ZDDP films 

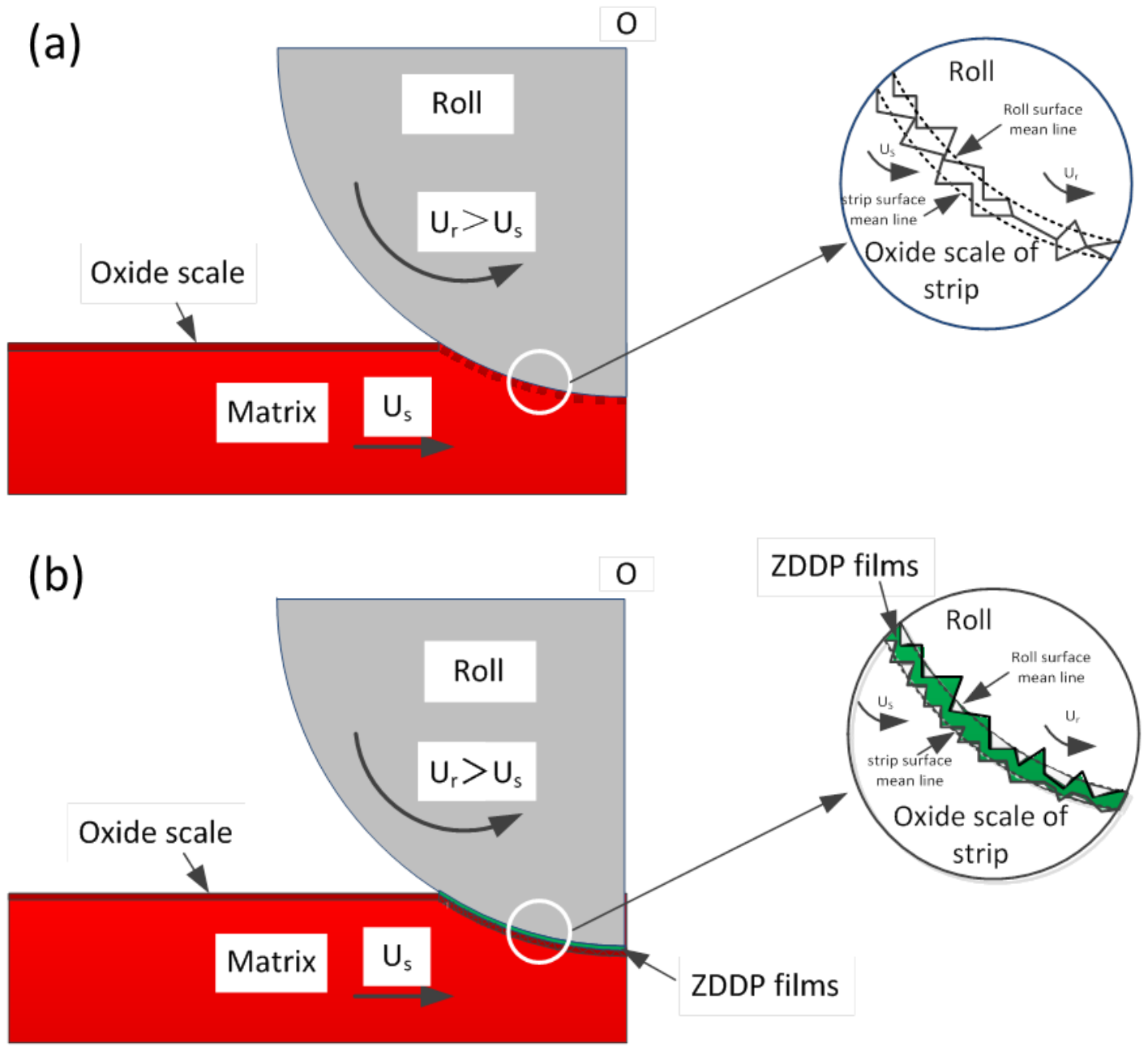

Figure 7 Mechanism of the deformation behaviour of the oxide scale in the roll bite (a) without and (b) with ZDDP films [7] 